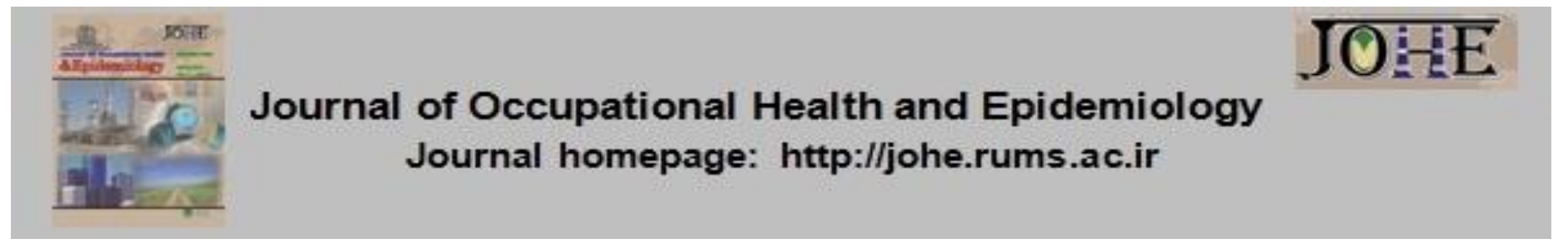

\title{
Postpartum depression and sleep disorders among working women with social support, referring to Health Centers in Shiraz, Iran, 2018 - 2019
}

\author{
Masumeh Rahimi ${ }^{1}$, Nahid Karimi ${ }^{2}$, Maryam Sedighi ${ }^{3}$, Sara Mousavi ${ }^{4^{*}}$ \\ 1- MSc in Clinical Psychology, Department of Psychology, Faculty of Educational Sciences \& Psychology, University of Kharazmi, \\ Tehran, Iran. \\ 2- MSc in Clinical Psychology, Department of Psychology, Faculty of Educational Sciences \& Psychology, Islamic Azad University, \\ Shiraz Branch, Shiraz, Iran. \\ 3- MSc in General Psychology, Department of Psychology, Faculty of Educational Sciences \& Psychology, Islamic Azad University, \\ Roudehen Branch, Tehran, Iran. \\ 4- Instructor, Department of Psychology, Payame Noor University, Tehran, Iran.
}

\section{Article Info}

* Corresponding author:

Sara Mousavi,

E-mail:

saramhasti@yahoo.com

\section{Article history}

Received: Jun, 2019

Accepted: Aug, 2019

10.29252/johe.8.3.141

Print ISSN: 2251-8096 Online ISSN: 2252-0902

Peer review under responsibility of Journal of Occupational Health and Epidemiology
Citation: Rahimi M, karimi N, Sedighi M, Mousavi S. Postpartum depression and sleep disorders among working women with social support, referring to Health Centers in Shiraz, Iran, 2018 - 2019. JOHE 2019; 8(3):141-7.

\begin{abstract}
Background: Postpartum depression (PPD) is a significant health problem that affects women's health. Tthe purpose of this study was to predict sleep disorders and postpartum depression based on the social support provided for employed women referred to health centers in Shiraz, Iran, from 2018 to 2019.

Materials \& Methods: A descriptive study was conducted on 90 working mothers, who were assessed 4 weeks after childbirth at health centers in Shiraz, from November 13 to December 13, 2018. The participants were selected through a multi-stage random sampling method. Data collection was done using the Standard Pittsburgh Sleep Quality Index (PSQI), Edinburgh Postnatal Depression Questionnaire (EPDS), and Multidimensional Scale of Perceived Social Support (MSPSS). Data were analyzed via Pearson's simple correlation coefficient and multivariate regression.

Results: Regression analysis showed significant correlations between social support, postpartum depression, and sleep disturbances in respondents (MR=0.409 and $\mathrm{p}$ $<0.001$ ). Social support dimensions can predict about $17 \%$ of the variance in the postpartum and sleep disturbance among women. There was not a significant correlation between social support and postpartum depression.

Conclusion: During the postpartum period, health practitioners should provide psychological education or counseling, and emphasize social support, particularly for spouses.
\end{abstract}

Keywords: Postpartum, Sleep Disorder, Social Support

\section{Introduction}

Postpartum depression (PPD) is described as a psychological mood disorder that takes place in a mom one or two months after childbirth, or it may begin some months after the infant's delivery (1). This period refers to mood disorders that may have been started or expanded during the postpartum period. It has a high effect on mom health, family functioning, and child improvement (2). The fifth edition of the diagnostic and statistical manual (DSM-V) described postpartum depression as a major depression along with the care of postpartum onset, a diagnosis that can be utilized signs manifest throughout being pregnant and within the four weeks after delivery (3). Some women may not experience PPD; however, mothers who are most at risk have a history of depression (4), substance use problems (5), high stress in life (6), poor socioeconomic status (7), 
and lack of social support $(8,9)$; also they might be single (10) or old mother (11). PPD is understood to have brought damages or harms to the personal mom adjustment, marital relationship, and motherinfant communication (1). Postpartum depression can lead to (in rare cases) maternal suicide or even kill the infant if left untreated (12).

In the postpartum period, certain groups of mothers are at a greater risk of developing depression. Working mothers are especially prone to workplace stressors and sleep disturbances due to caring of newborn babies; then they are more at risk of health problems because of work activities to meet the family needs (13). Moreover, Gurudatt in a study reported a higher degree of depression in the initial months after delivery both in working and non-working women (14). Furthermore, the findings indicate a high rate of depression in housewives (15). As stated earlier, several studies have described working mothers as risk factors for developing PPD; however, the results are controversial and contradictory in this regard (1315). Among Turkish women, the occurrence of PPD was found to be $23.8 \%$ (16). Just like all over the world, PPD is a common issue among Iranian women (17).

One crucial but often neglected change after child delivery is the increased risk of sleep deprivation that causes a problem for mother health (18). There is emerging evidence to suggest that women with significant sleep disturbance, characterized by insomnia signs and/or poor sleep quality, are more presumably to develop PPD (19). Significant subsequences may arise as a result, including maternal-infant attachment, effective care of the infant, and behavioral or emotional difficulties in the infant (19). Sleep disorders in mothers may cause marital dissatisfaction among couples as well (20). Early parenthood is a period of endless rest in which parents are at increased depression risk. Poor sleep and rest quality have been distinguished both as an indicator of childcare burdensome side effects and their outcome (20). In the perinatal period, sleep and mood disorder are usually reported by women (21).

In the postpartum period, women may not have sufficient time for sleep; the newborn baby needs attention and disturbs mothers sleep in the first months after childbirth (22). Having psychosocial support during pregnancy and after delivery is of great importance in preventing depression (23). According to the emphasis on social support as an important factor in the admission of maternity (24), there are various kinds of social supports by family, spouse, friends, and peers (25). A study showed that support from husbands and families was expected and many women believed this support should be provided without demanding (26). Some of the studies in this area confirmed that associative support positively influences the tendency of the woman to the motherhood role at the maternity and the postpartum period; thus, it strengthens an infant-mother relationship $(27,28)$. In the literature, risk elements for postpartum depression are examined; however, a woman's partner or spouse is generally regarded to be the primary source of support (29). Indeed, support from the husband has been found to be a consistent and substantial protective factor for postpartum depression (30). Better social support received from partners during pregnancy is accompanied by lower postpartum emotional distress (31); those mothers, who have PPD, reported that it was effective to have a supportive partner to assist them in coping with depressive symptoms (32).

Prevalence of postpartum depression was found to be high. Therefore, it is necessary to pay attention to this problem, especially among working women. Studies are required to find methods of supporting working women with PPD. According to previous studies, there has been less investigation of PPD among working women. Thus, this study aimed to predict postpartum depression and sleep disturbances on the basis of social support among working women referred to health centers in Shiraz.

\section{Materials and Methods}

This descriptive study was performed on a census sample of 90 delivered women attending 6 health care centers in Shiraz. Participants were selected based on a multi-stage random sampling by the lottery method. The criteria for entering the study include working women between twenty and thirtynine years old, having a healthy child without a history of depression, and receiving a score up to 13 in the Edinburgh depression questionnaire. Dissatisfaction with participation in the research, as well as having more than 40 years old and a history of mood disorders or depression excluded people from the study. Before the data collection, participants were explained concerning the aim and usage of data, as well as the confidentiality of the collected sample. Required data, such as age, education, delivery number, and occupation, were collected from participants through their medical record at health care centers. Other information collected from the questionnaires, including the Standard Pittsburgh Sleep Quality Index (PSQI), Edinburgh Postnatal Depression Questionnaire 
(EPDS), and Multidimensional Scale of Perceived Social Support (MSPSS).

In order to collect the samples for this research for a month from November 13 to December 13, 2018, the health centers of Shiraz in districts 1 and 2 were selected. Out of these two districts, health centers were randomly picked up, and according to the inclusion and exclusion criteria mentioned earlier participants were selected. It is necessary to mention that the number of qualified people was 115 , among them, 25 were excluded from the analysis process due to incomplete and misleading questionnaires. At each center, at first, participants were familiarized with the goal of the study besides explaining to them that it is not necessary to mention personal information. The study was also done according to the participants' opinions without any compulsion. Those people who were referred to the health centers for monthly checkups of their infants in the waiting room responded to the questionnaire, in which all the Declaration of Helsinki were considered.

PSQI is a self-report questionnaire that is done over 19-items. It creates 7 components, which produce one global score of sleep quality and disturbances during the postnatal period (33). The PSQI measures several aspects of sleep, offering seven component scores and one composite score. Each item is weighted on a $0-3$ interval scale. In scoring the PSQI, seven component scores are derived, from 0 (no difficulty, very good) to 3 (severe difficulty, very bad). The component scores are summed to produce a global score (range 0 to 21). Higher scores indicate worse sleep quality and where lower scores denote healthier sleep quality. The component scores consist of subjective sleep quality, sleep latency (i.e., how long it takes to fall asleep), sleep duration, habitual sleep efficiency (i.e., the percentage of time that one is asleep), sleep disturbances, use of sleeping medication, and daytime dysfunction.

This scale has good internal consistency, testretest reliability, and validity (33). In Iranian version, sensitivity and specificity of discrimination in insomniac patients from control subjects were $94 \%$ and $72 \%$ for a PSQI cutoff value of 5 , as well as $85 \%$ and $84 \%$ for a PSQI cutoff value of 6 (34). Cronbach's alpha coefficient for all subjects was $0.77,0.52$ for the patient group, and 0.78 for the control group (34).

This scale encompasses ten items, and each item is rated on a four-point scale, the maximum scores of 30 . A score of 13 or upper is considered to be a significant 'case' of postnatal depression; scores between 10 to12 represent 'borderline' and 0 to 9 'not depressed' (35). In the Iranian version of this scale, the Cronbach's alpha was ranged from 0.7 to 0.79 (36).

Zimet et al. developed the 12-question MSPSS in 1998; it was used for subjective evaluation of social support (37). MSPSS is a Likert type scale that is rated as 7. It provides response options of 0 (very strongly disagree), 1(strongly disagree), 2(Mildly disagree), 3(Neutral), 4(Mildly agree), 5(strongly agree), and 6(very strongly agree). Cronbach $\alpha$ has an internal consistency of 0.95 for family support, 0.94 for friend support, 0.91 for special person's support, and 0.94 for total scale (38). In this study, Cronbach a, has internal coordination 0.92 for family support, 0.92 for friend support, 0.88 special person's support, and 0.94 for the total scale. In Iran, Cronbach's a coefficient for friends, important people, and family subscales for the patient sample was, $0.89,0.92$, and 0.87 , respectively; it was 0.92 for the scale as a whole (39).

Data were analyzed using SPSS v.23. To demonstrate the initial results, Pearson's simple correlation coefficient and multivariate regression were used to examine the prediction of sleep disturbances and postpartum depression through the social support variable among working women. The cutoff for determining significance was $p<.05$.

\section{Results}

As shown in Table 1, the mean age of mothers was 26.65 \pm 5.08 years (age range: 20-39). Demographic characteristics, i.e., mother's delivery number, education, age, and occupation, are presented in Table 1.

Table 1: Frequency \& percentage of demographic variables of working women, who referred to health centers in 20182019

\begin{tabular}{|c|c|c|c|}
\hline Variable & Group & Frequency & Percentage \\
\hline \multirow{3}{*}{ Delivery number } & 1 & 41 & 45.55 \\
\hline & 2 & 42 & 46.66 \\
\hline & 3 & 7 & 7.77 \\
\hline \multirow{3}{*}{ Education } & $\mathrm{BA}$ & 49 & 54.44 \\
\hline & MA & 36 & 40 \\
\hline & Ph.D. & 5 & 5.55 \\
\hline \multirow{3}{*}{ Age } & 20 to24 & 10 & 11.11 \\
\hline & 25 to 31 & 43 & 47.77 \\
\hline & 32 to 39 & 37 & 41.11 \\
\hline \multirow{2}{*}{ Occupation } & Working at office & 35 & 38.88 \\
\hline & Working at school & 55 & 61.11 \\
\hline
\end{tabular}


As shown in Table (2), the mean \pm SD score of sleep disturbance was $27.81 \pm 4.65$; these results indicate that the level of postpartum sleep disorders is moderate. The mean score of mothers' postpartum depression was found to be $15.23 \pm 4.47$; these results show that the rate of depression in women after delivery is higher than the average. As a result, the mean score of social support was $27.65 \pm 4.48$; these results indicate that family support has the highest mean in working women.

Table2: Mean, standard deviation, minimum and maximum scores of postpartum sleep disorders, depression, and social support of women in Shiraz, Iran, 2018-19

\begin{tabular}{clcccc}
\hline & Variable & Mean & SD & Max & Min \\
\hline & Sleep disorders & 9.46 & 2.94 & 15 & 2 \\
\hline & Postpartum depression & 15.23 & 4.47 & 5 & 23 \\
\hline \multirow{3}{*}{ Social support } & Friend support & 22.26 & 5.50 & 13 & 60 \\
\cline { 2 - 6 } & Family support & 27.81 & 4.65 & 18 & 60 \\
\cline { 2 - 6 } & Other support & 27.65 & 4.48 & 18 & 60 \\
\cline { 2 - 6 } & Total social support & 77.76 & 13.82 & 50 & 113 \\
\cline { 2 - 6 } & & &
\end{tabular}

As shown in Table (3), regression analysis by inter method shows that the multiple correlations between social support and postpartum sleep disturbances in working women were significant $(\mathrm{MR}=0.409$ and $\mathrm{p}<0.001)$. That is, through the social support, about $17 \%$ of the variance in the variable of the postpartum sleep disturbance among women can be predicted.

Meanwhile, the regression coefficients showed that the other support with a beta of 0.78 and family support with a beta of 0.73 could predict the postpartum sleep disturbance; they are the best predictor of the postpartum sleep disturbance criterion in working women. In addition, there was not a significant correlation between social support and postpartum depression $\mathrm{MR}=0.107$ and $\mathrm{p}$ $<0.88$. That is, through the social support dimensions, only about 0.01 percent of the variance in the criterion variable of the postpartum depression among working women can be predicted, which is negligible.

Also, according to the results of the correlation coefficient shown in the Table, there is not a significant relationship between the dimensions of social support and postpartum depression of working women.

Table 3: Multivariate correlation coefficients (input method) between social support with sleep disorders and postpartum depression among women in Shiraz, Iran, in 2018-19

\begin{tabular}{|c|c|c|c|c|c|c|}
\hline Criteria variable & $\begin{array}{c}\text { Indexes of } \\
\text { predicting variable }\end{array}$ & MR & $\mathbf{R 2}$ & $\mathbf{F}$ & $\mathbf{P}$ & $\begin{array}{c}\text { Coefficient of } \\
\text { regression }\end{array}$ \\
\hline \multirow{5}{*}{ Sleep disorders } & Friend support & \multirow{5}{*}{0.409} & \multirow{5}{*}{0.167} & \multirow{5}{*}{3.74} & \multirow{5}{*}{$P=0.001$} & $\begin{array}{c}B=0.05 \\
t=0.24 \\
P=0.81\end{array}$ \\
\hline & Family support & & & & & $\begin{array}{c}B=0.73 \\
t=2.21 \\
P=0.007\end{array}$ \\
\hline & & & & & & $B=0.78$ \\
\hline & Other support & & & & & $\begin{array}{c}t=3.02 \\
P=0.004\end{array}$ \\
\hline & Total social support & & & & & $\begin{array}{l}B=0.05 \\
t=0.24 \\
P=0.81\end{array}$ \\
\hline \multirow{5}{*}{ Postpartum depression } & Friend support & \multirow{5}{*}{0.107} & \multirow{5}{*}{0.01} & \multirow{5}{*}{0.21} & \multirow{5}{*}{$P=0.88$} & $\begin{array}{l}B=0.06 \\
t=0.28 \\
P=0.77\end{array}$ \\
\hline & Family support & & & & & $\begin{array}{l}B=0.21 \\
t=0.75\end{array}$ \\
\hline & & & & & & $P=0.45$ \\
\hline & Other support & & & & & $\begin{array}{l}B=0.09 \\
t=0.33 \\
P=0.77\end{array}$ \\
\hline & Total social support & & & & & $\begin{array}{c}B=0.06 \\
t=0.28 \\
P=0.77\end{array}$ \\
\hline
\end{tabular}




\section{Discussion}

Women have many responsibilities of their families; they take care of their families, fulfill the demands of their husbands, and meet expectations of society. According to the mentioned responsibilities, our findings suggest that social support dimensions can predict sleep disturbance and postpartum depression. These results indicate that there is a significant relationship between social support and sleep disturbances among women. In addition, results specify that there is no significant relationship between social support and postpartum depression of working women.

In line with the results of this study, the research literature shows that women, who have had enough sleep, are less likely to get PPD (19-22). Mothers with poor sleep have been linked to perceiving distress or depression by the infant (40). Sleep deprivation is a potential factor, which can be associated with postpartum depression (41). The potential role of the partner will help to improve mother and infant welfare postpartum, relationships in mental health interventions with possible benefits to babies (31). Getting social supports after birth, especially from the spouse for mothers of all ages is important to decrease the risk of PPD (42).

Women who receive social support are less likely to report depressive symptoms during pregnancy (43). Dibaba et al. stated that social support during pregnancy plays a protecting role in depression (43). Women who had social support during pregnancy delivered a child with more weight (45). On the other hand, women who missed adequate social support had a higher risk of pregnancy complications, such as feticide, pre-eclampsia, and preterm births (40).

The results of the studies showed that $28 \%$ of women had postpartum depression, and the mean of depression marks was high among the housekeepers $(15,46)$ Conversely, certain studies revealed that employed women had higher levels of postpartum depression $(48,49)$ This may be due to the fact that working mothers had to deal with harder responsibilities. Thus, greater exposures to the hardness of working outside home tend to increase the amount of situational anxiety in working mothers. Issues that can occur as a result of PPD in the workplace are absenteeism and low work performance (13). On the other hand, nonworking mothers are just concerned with their household field. Therefore, they have less scope to deal with an external stressful situation. Their unique role creates less pressure in their life and situation; and hence, anxiety is less prominent in them than those of employed mothers (49).

The finding may be delineated to the very fact that working mothers totally involved with several works simultaneously as they had not enough time for creating fancy leisure; nevertheless, the sensation of losing interest was less tough by working mothers than non-working ones. Besides, these working mothers could not provide much time for their family and kids so that they feel guilty. This was the main explanation for the upper level of depression among working mothers than nonworking ones. Stressful life events were the prime reason for depression; for working women, balancing the job, as well as the household may also lead to depression. On the other hand, nonworking mothers typically bore the foremost responsibilities for housework \& childcare. Their attention was continuously engaged by their children and household tasks; however, the working mothers could not share this family bonding (49).

Results showed that there is no significant relationship between social support and postpartum depression of working women. It should be noted that the involvement of husbands in filling in questionnaires at the stage of implementation had a significant impact on the results. On the other hand, the limitation of this study was that the mothers did not have adequate time to complete the questionnaires because of the nutrition and care of infants. Due to the qualitative nature of the study, the results cannot be made public to the population of postpartum women as a whole.

\section{Conclusion}

Working women who have little social support, poor health, and a history of stressful life events are in danger of poor psychological state throughout the perinatal period.

\section{Acknowledgement}

We would like to express our appreciation to participants for their help in the completion of this research. Without their help, this study would not have been possible to be completed.

Conflict of interest: None declared.

\section{References}

1. Odinka JI, Nwoke M, Chukwuorji JC, Egbuagu K, Mefoh P, Odinka PC, et al. Post-partum depression, anxiety and marital satisfaction: A perspective from Southeastern Nigeria. S Afr J Psychiatr 2018; 24:1109. 
2. American Psychiatric Association. DSM. History [Internet]. 2013 [updated 2013 Jul 1; cited 2019]. Available from: http://www.psychiatry.org/practice/dsm/ds m-history-of-the-manual

3. Miller ML, Kroska EB, Grekin R. Immediate postpartum mood assessment and postpartum depressive symptoms. J Affect Disord 2017; 207:69-75.

4. Chi X, Zhang P, Wu H, Wang J. Screening for Postpartum Depression and Associated Factors Among Women in China: A Cross-Sectional Study. Front Psychol 2016; 7:1668.

5. Chapman SL, Wu LT. Postpartum substance use and depressive symptoms: a review. Women Health 2013; 53(5):479-503.

6. Qobadi M, Collier C, Zhang L. The Effect of Stressful Life Events on Postpartum Depression: Findings from the 2009-2011 Mississippi Pregnancy Risk Assessment Monitoring System. Matern Child Health J 2016; 20(Suppl 1):164-72.

7. Dolbier CL, Rush TE, Sahadeo LS, Shaffer ML, Thorp J; Community Child Health Network Investigators. Relationships of race and socioeconomic status to postpartum depressive symptoms in rural African American and nonHispanic white women. Matern Child Health J 2013; 17(7):1277-87.

8. Alhasanat-Khalil D, Fry-McComish J, Dayton C, Benkert R, Yarandi H, Giurgescu C. Acculturative stress and lack of social support predict postpartum depression among U.S. immigrant women of Arabic descent. Arch Psychiatr Nurs 2018; 32(4):530-5.

9. Pao C, Guintivano J, Santos H, Meltzer-Brody S. Postpartum depression and social support in a racially and ethnically diverse population of women. Arch Womens Ment Health 2019; 22(1):105-14.

10. Abrams LS, Dornig K, Curran L. Barriers to service use for postpartum depression symptoms among low-income ethnic minority mothers in the United States. Qual Health Res 2009; 19(4):535-51.

11. Muraca GM, Joseph KS. The association between maternal age and depression. J Obstet Gynaecol Can 2014; 36(9):803-10.

12. Qandil S, Jabr S, Wagler S, Collin SM. Postpartum depression in the Occupied Palestinian Territory: a longitudinal study in Bethlehem. BMC Pregnancy Childbirth 2016; 16(1):375.

13. Selix NW, Goyal D. Postpartum Depression among Working Women: A Call for Practice and Policy Change. The Journal for Nurse Practitioners 2015; 11(9):897-902.

14. Gurudatt N. Postpartum Depression in Working and Non-Working Women. International Proceedings of Economics Development and Research 2014; 78:69-73.

15. Mohammadi A, Adalatzadeh Aghdam G, Ranji S. Comparison of Postpartum Depression of
Working Women and Housewives and its Relationship with Social Support and Marital Adjustment. Procedia Soc Behav Sci 2011; 30:1837-9.

16. Özcan NK, Boyacıoğlu NE, Dinç H. Postpartum Depression Prevalence and Risk Factors in Turkey: A Systematic Review and MetaAnalysis. Arch Psychiatr Nurs 2017; 31(4):4208.

17. Veisani Y, Delpisheh A, Sayehmiri K, Rezaeian S. Trends of postpartum depression in Iran: a systematic review and meta-analysis. Depress Res Treat 2013; 2013:291029.

18. Murphey C, Carter P, Price LR, Champion JD, Nichols F. Psychological Distress in Healthy Low-Risk First-Time Mothers during the Postpartum Period: An Exploratory Study. Nurs Res Pract 2017; 2017:8415083.

19. Okun ML. Disturbed Sleep and Postpartum Depression. Curr Psychiatry Rep 2016; 18(7):66

20. Saxbe DE, Schetter CD, Guardino CM, Ramey SL, Shalowitz MU, Thorp J, et al. Sleep Quality Predicts Persistence of Parental Postpartum Depressive Symptoms and Transmission of Depressive Symptoms from Mothers to Fathers. Ann Behav Med 2016; 50(6):862-75.

21. Bei B, Coo S, Trinder J. Sleep and Mood during Pregnancy and the Postpartum Period. Sleep Med Clin 2015; 10(1):25-33.

22. Dørheim SK, Bjorvatn B, Eberhard-Gran M. Can insomnia in pregnancy predict postpartum depression? A longitudinal, population-based study. PLoS One 2014; 9(4):e94674.

23. Morikawa M, Okada $T$, Ando $M$, Aleksic B, Kunimoto S, Nakamura $\mathrm{Y}$, et al. Relationship between social support during pregnancy and postpartum depressive state: a prospective cohort study. Sci Rep 2015; 5:10520.

24. Abdollahpour S, Keramat A. The Relationship between Perceived Social Support from Family and Postpartum Empowerment with Maternal Wellbeing in the Postpartum Period. Journal of Midwifery and Reporoductive Health 2016; 4(4):779-87.

25. Muñoz-Laboy M, Severson N, Perry A, Guilamo-Ramos V. Differential impact of types of social support in the mental health of formerly incarcerated Latino men. Am J Mens Health 2014; 8(3):226-39.

26. Negron R, Martin A, Almog M, Balbierz A, Howell EA. Social support during the postpartum period: mothers' views on needs, expectations, and mobilization of support. Matern Child Health J 2013; 17(4):61623.

27. Tambag H, Turan Z, Tolun S, Can R. Perceived social support and depression levels of women in the postpartum period in Hatay, Turkey. Niger $\mathrm{J}$ Clin Pract 2018; 21(11):1525-30

28. Corrigan CP, Kwasky AN, Groh CJ. Social Support, Postpartum Depression, and Professional Assistance: A Survey of Mothers in 
the Midwestern United States. J Perinat Educ 2015; 24(1):48-60.

29. Gremigni $P$, Mariani L, Marracino V, Tranquilli AL, Turi A. Partner support and postpartum depressive symptoms. J Psychosom Obstet Gynecol 2011; 32(3):135-40.

30. Yim IS, Tanner Stapleton LR, Guardino CM, Hahn-Holbrook J, Dunkel Schetter C. Biological and psychosocial predictors of postpartum depression: systematic review and call for integration. Annu Rev Clin Psychol 2015; 11:99137.

31. Stapleton LR, Schetter CD, Westling E, Rini Ch, Glynn LM, Hobel CJ, et al. Perceived partner support in pregnancy predicts lower maternal and infant distress. J Fam Psychol 2012; 26(3):453-63.

32. Werner E, Miller M, Osborne LM, Kuzava S, Monk C. Preventing postpartum depression: review and recommendations. Arch Womens Ment Health 2015; 18(1):41-60.

33. Buysse DJ, Reynolds CF 3rd, Monk TH, Berman SR, Kupfer DJ. The Pittsburgh Sleep Quality Index: a new instrument for psychiatric practice and research. Psychiatry Res 1989; 28(2):193-213.

34. Farrahi Moghaddam J, Nakhaee N, Sheibani V, Garrusi B, Amirkafi A. Reliability and validity of the Persian version of the Pittsburgh Sleep Quality Index (PSQI-P). Sleep Breath 2012; 16(1):79-82.

35. Cox JL, Holden JM, Sagovsky R: Detection of postnatal depression: development of the 10item Edinburgh Postnatal Depression Scale. $\mathrm{Br}$ J Psychiatry 1987; 150:782-6.

36. Rahmani Ivary F, Fanaei S, Ghahremani S, Falah Ardizi N, Abdollahpour N, Khorsandi F, et al. A Systematic Review of Psychometric Properties of the Edinburgh Postnatal Depression Scale in Iranian Population. International Journal of Pediatrics 2019; 7(5): 9497-505.

37. Zimet GD, Dahlem NW, Zimet SG, Farley GK. The multidimensional scale of perceived social support. J Pers Assess 1988; 52(1):30-41.

38. Eker D, Arkar H. Factorial structure, validity, and reliability of revised from of the multidimensional scale of perceived social support. Turkish of Journal Psychiatry 2001; 12(1):17-25.

39. Bagherian-Sararoudi R, Hajian A, Ehsan HB, Sarafraz MR, Zimet GD. Psychometric properties of the persian version of the multidimensional scale of perceived social support in Iran. Int J Prev Med 2013; 4(11):1277-81.

40. Elsenbruch $S$, Benson $S$, Rücke $M$, Rose $M$, Dudenhausen J, Pincus-Knackstedt MK, et al. Social support during pregnancy: effects on maternal depressive symptoms, smoking and pregnancy outcome. Hum Reprod 2007; 22(3):869-77.

41. Iranpour S, Kheirabadi GR, Esmaillzadeh A, Heidari-Beni M, Maracy MR. Association between sleep quality and postpartum depression. J Res Med Sci 2016; 21:110.

42. Kim TH, Connolly JA, Tamim H. The effect of social support around pregnancy on postpartum depression among Canadian teen mothers and adult mothers in the maternity experiences survey. BMC Pregnancy Childbirth 2014; 14:162.

43. Dibaba Y, Fantahun M, Hindin MJ. The association of unwanted pregnancy and social support with depressive symptoms in pregnancy: evidence from rural Southwestern Ethiopia. BMC Pregnancy Childbirth 2013; 13:135.

44. Liabsuetrakul T, Vittayanont A, Pitanupong J. Clinical applications of anxiety, social support, stressors, and self-esteem measured during pregnancy and postpartum for screening postpartum depression in Thai women. J Obstet Gynaecol Res 2007; 33(3):333-40.

45. Abadi MNL, Ghazinour M, Nygren L, Nojomi M, Richter J. Birth weight, domestic violence, coping, social support, and mental health of young Iranian mothers in Tehran. J Nerv Ment Dis 2013; 201(7):602-8.

46. Aghapoor M, Mohammadi A. Comparison postpartum depression of working women and housewives, and its relationship with social support and marital adjustment. Woman and Study of Family 2009; 1(4):9-32.

47. Dawood E, Habib F. Comparison of Depression and Anxiety between Housewife and Employed Pregnant Women. International Journal of Nursing 2018; 5(2):23-31.

48. Adhikari H. Anxiety and Depression: Comparative Study between Working and NonWorking Mothers. Global Journal of Human Social Science Research 2012; 12(12):1-9.

49. Myors KA, Schmied V, Johnson M, Cleary M. 'My special time': Australian women's experiences of accessing a specialist perinatal and infant mental health service. Health Soc Care Community 2014; 22(3):268-77. 